\title{
Outbreak of Nosocomial Urinary Tract Infections Caused by Serratia marcescens
}

\author{
TOSHIRO OKUDA, ${ }^{1}$ NOBUKO ENDO,,${ }^{1}$ YASUAKI OSADA, ${ }^{2 *}$ AND HIROSHI ZEN-YOJI ${ }^{1}$ \\ Department of Microbiology and Immunology, School of Health Science, Kyorin University, Tokyo 192, ${ }^{1}$ and Research \\ Institute, Daiichi Seiyaku Co., Ltd., Tokyo 134, ${ }^{2}$ Japan
}

Received 7 February 1984/Accepted 18 June 1984

\begin{abstract}
A prolonged outbreak (December 1980 to July 1982) of nosocomial urinary tract infections appeared to be due to strains of Serratia marcescens that were resistant to currently available antibiotics. The serotyping and antibiotic susceptibility patterns suggested a few endemic strains of serotypes $013,02 / 3,012 / 14$, and nontypable strains. These strains were isolated from the urine samples of inpatients with urinary tract infections in the urology ward and in other wards. The strains of 012/14 (gentamicin susceptible) were replaced with those of 02/3 (gentamicin resistant) between June and September 1981, whereas the other serotypes were isolated continuously. They were resistant to sulbenicillin, cefmetazole, gentamicin, and amikacin, and susceptible to micronomicin and ofloxacin, a new quinolone antibiotic. Most of them were also resistant to the disinfectant chlorhexidine, which had been used widely for hand washing in the hospital.
\end{abstract}

During the past decade, Serratia marcescens has been encountered as a formidable nosocomial pathogen, particularly of the urinary tract and respiratory tract $(1,2,8-11,16$, $17,20)$. In some hospitals, a definite strain or serotype with an unusual antimicrobial susceptibility pattern has caused an epidemic of limited duration $(11,17)$. Most of the strains reported have been highly resistant to the currently available antibiotics, except to a few aminoglycosides, including gentamicin and amikacin (4, 18, 19). Recently, however, increasing numbers of reports have pointed out the rise in epidemics due to strains resistant even to gentamicin or to amikacin $(3,5,6,12,15,18)$, thus posing difficulties in the control of $S$. marcescens infections.

We recently experienced a nosocomial outbreak of urinary tract infection (UTI) with a few serologically different strains of $S$. marcescens. During the events, a bacterial substitution possibly due to an antibiotic employed was noticed. Through the susceptibility testings, ofloxacin, an antibiotic of greater potency than the currently available antibiotics, was found to be useful.

\section{MATERIALS AND METHODS}

Bacteria. A total of 192 strains of $S$. marcescens isolated from the urine samples of patients with UTI hospitalized in Kyorin University Hospital, Tokyo, Japan, from 1980 to 1982 were used. In all cases, the colony counts exceeded $10^{5} / \mathrm{ml}$, and no colony was pigmented. After being serotyped, they were preserved at room temperature in a semisolid agar medium made by adding $0.4 \%$ Oxoid agar no. 3 (Oxoid Ltd., London) to brain heart infusion (BHI) broth (Nissui Seiyaku Co., Ltd., Tokyo).

Serotyping. The serotype of each strain was determined by an agglutination test, using the specific antisera to $O$ antigens of S. marcescens (Denka Seiken Co., Ltd., Tokyo). Overnight cultures of each strain on heart infusion agar medium (Nissui Seiyaku Co.) at $37^{\circ} \mathrm{C}$ were suspended in physiological saline and killed by heating at $120^{\circ} \mathrm{C}$ for $20 \mathrm{~min}$. After cooling, the bacterial suspensions were centrifuged at 3,000

\footnotetext{
* Corresponding author.
}

rpm for $30 \mathrm{~min}$, and the sediments were resuspended in physiological saline at a concentration of $1 \mathrm{mg} / \mathrm{ml}$ for use as antigens. Samples $(0.5 \mathrm{ml})$ of the antigens were poured into small test tubes containing $0.1 \mathrm{ml}$ of specific antisera, and the test tubes were placed overnight in a refrigerator after incubation at $50^{\circ} \mathrm{C}$ for $2 \mathrm{~h}$ with shaking. The antigen that aggregated macroscopically in one test tube was designated as the $\mathrm{O}$ antigen corresponding to the specific $\mathrm{O}$ antiserum in the test tube.

MICs. For each strain, the MICs of the antibiotics and of a disinfectant, chlorhexidine, were measured by the agar dilution method. The overnight cultures in $\mathrm{BHI}$ broth at $37^{\circ} \mathrm{C}$ were adjusted to $0.5 \mathrm{McF}$ arland standard by the addition of fresh BHI broth to the cultures, equivalent to $10^{8} \mathrm{CFU} / \mathrm{ml}$, and then were diluted 1:100 $\left(10^{6} \mathrm{CFU} / \mathrm{ml}\right)$ with fresh BHI broth. By using a semiautomatic inoculator, Micro Planter (Maeda Factory Ltd., Tokyo), we spotted the bacterial suspensions on BHI agar plates containing antibiotics or chlorhexidine. After incubation of the plates, the minimal drug concentrations that prevented the formation of more than five colonies on the plates were defined as the MICs.

Antibiotics and disinfectant. The antibiotics tested were as follows: sodium sulbenicillin (Takeda Chemical Industries, Ltd., Osaka), sodium cefmetazole (Sankyo Co., Ltd., Tokyo), gentamicin sulfate (Shionogi \& Co., Ltd., Osaka), amikacin sulfate (Banyu Pharmaceutical Co., Ltd., Tokyo), micronomicin sulfate (Kyowa Hakko Co., Ltd., Tokyo), and ofloxacin (Daiichi Seiyaku Co., Ltd., Tokyo). For a disinfectant, we used chlorhexidine gluconate (ICI Pharmaceutical Inc., Tokyo). Chlorhexidine and the antibiotics other than ofloxacin were dissolved in sterile distilled water at concentrations of 4,000 and $1,000 \mu \mathrm{g} / \mathrm{ml}$ and diluted serially twofold to 31.2 and $2 \mu \mathrm{g} / \mathrm{ml}$, respectively. Ofloxacin was dissolved in $0.1 \mathrm{~N}$ sodium hydroxide and diluted with sterile distilled water in the same manner. The agar plates were prepared by mixing 2-ml quantities of each dilution of the drugs with 18 $\mathrm{ml}$ of BHI agar medium in a plastic petri dish $(90 \mathrm{~mm}$ in diameter), so that the concentrations of chlorhexidine and the antibiotics ranged from 3.12 to 400 and from 0.2 to 100 $\mu \mathrm{g} / \mathrm{ml}$, respectively. 


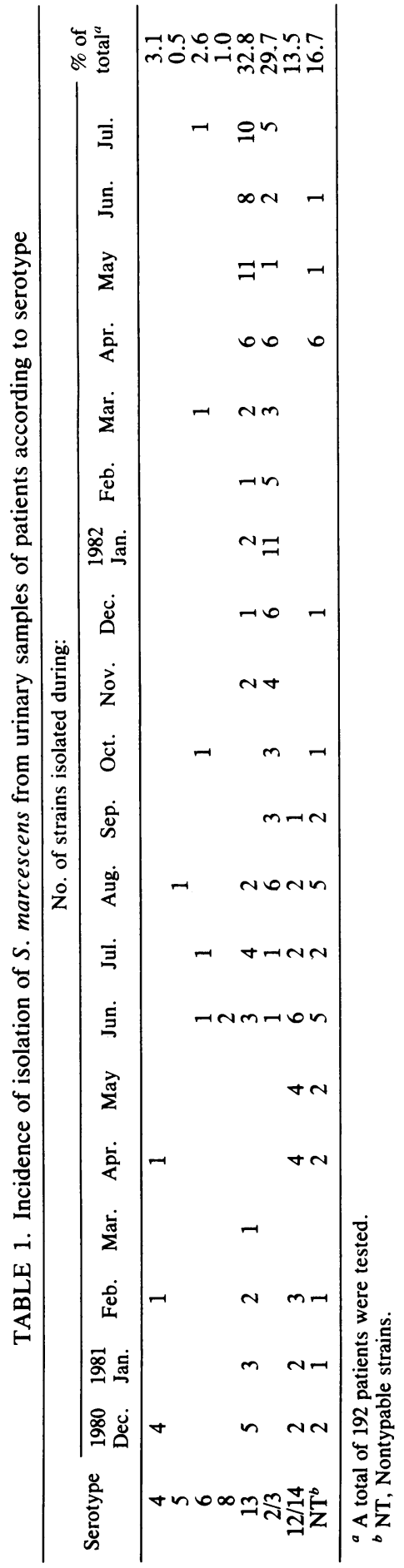

\section{RESULTS}

Incidence of isolation of causative $S$. marcescens. From December 1980 to July 1982, strains of $S$. marcescens were isolated from the urine samples of 192 of $1,039(18.5 \%)$ inpatients with UTI. They were grouped into seven serotypes, except for $32(16.7 \%)$ nontypable (NT) strains; the major types were $013,02 / 3$, and $012 / 14$ (Table 1). The strains of $\mathrm{O} 13$ and NT were continuously isolated throughout the epidemic, and the O12/14 strains were replaced by those of O2/3 between June and September 1981. Tables 2 and 3 show the incidence of isolation of the three major serotypes and of NT according to each ward in buildings A and B of the hospital. At first, an outbreak of UTI due to O13 and NT was found in a surgical intensive care unit, neurosurgical ward, and the third department of internal medicine, located in building $\mathrm{B}$, and the strains were disseminated to other wards later. However, neither O13 nor NT was isolated from the patients in building A by October 1981 or by March 1982, respectively, thus indicating the dissemination of these strains from building B to building A. Serotype O12/14 was isolated from December 1980 to September 1981 throughout the wards in buildings $\mathrm{A}$ and $\mathrm{B}$ and disappeared later. In its place, serotype $\mathrm{O} 2 / 3$ was isolated frequently from all of the wards from June 1981 to July 1982, thus indicating a bacterial substitution from strains of $012 / 14$ to those of $\mathrm{O} 2 / 3$ in the wards (Table 3 ).

Antimicrobial susceptibility. The MICs of antibiotics for the major strains of $S$. marcescens belonging to the serotypes mentioned above are shown in Table 4. All of the strains tested were resistant to sulbenicillin, cefmetazole, and amikacin; the MICs of the $\beta$-lactam antibiotics and amikacin for $90 \%$ of the strains tested $\left(\mathrm{MIC}_{90}\right)$ were $>100$ $\mu \mathrm{g} / \mathrm{ml}$ and 25 to $50 \mu \mathrm{g} / \mathrm{ml}$, respectively. The strains of serotype $012 / 14$ were more susceptible to gentamicin than were the strains that replaced them $(\mathrm{O} 2 / 3)$ and the endemic strains (O13). The MICs for $50 \%$ of the strains tested $\left(\mathrm{MIC}_{50}\right)$ for strains of $\mathrm{O} 12 / 14, \mathrm{O} 2 / 3, \mathrm{O} 13$, and NT were 6.25, 50,100 , and $25 \mu \mathrm{g} / \mathrm{ml}$, respectively. Even the $\mathrm{MIC}_{90}$ for the strains of $012 / 14$ was $12.5 \mu \mathrm{g} / \mathrm{ml}$, whereas those for other strains were more than $100 \mu \mathrm{g} / \mathrm{ml}$. The strains of $012 / 14$ were also susceptible to micronomicin $\left(\mathrm{MIC}_{90}, 6.25 \mu \mathrm{g} / \mathrm{ml}\right)$, whereas others were less susceptible ( $\mathrm{MIC}_{90}, 12.5$ to $25 \mu \mathrm{g} /$ $\mathrm{ml}$ ). Ofloxacin, a new quinolone antibiotic for oral use, was as active as micronomicin against all of the strains tested. Table 5 shows the changes over time of the susceptibilities of these strains to the drugs tested. The strains of each serotype were divided into two groups; group A comprised the strains isolated by September 1981, when the bacterial substitution from $\mathrm{O} 12 / 13$ to $\mathrm{O} 2 / 3$ was observed, and group B consisted of those isolated subsequently, from October 1981 to July 1982. Both groups of bacteria were highly resistant to sulbenicillin and cefmetazole and were susceptible to micronomicin and ofloxacin. Most of the strains of O12/14 and O13 of group A were susceptible to gentamicin, the $\mathrm{MIC}_{50}$ for the former and latter strains being 6.25 and $1.56 \mu \mathrm{g} / \mathrm{ml}$, respectively. The strains of serotype $\mathrm{O} 13$ isolated later (group B) became resistant, so that the $\mathrm{MIC}_{50}$ and $\mathrm{MIC}_{90}$ became 100 and $>100$ $\mu \mathrm{g} / \mathrm{ml}$, respectively. On the other hand, the strains of $\mathrm{O} 2 / 3$ that replaced those of $012 / 14$ were resistant to the antibiotic. Most of the isolates, except for those of 013 of group A, were highly resistant to amikacin. Furthermore, most of the isolates, except for those of $012 / 14$, were also highly resistant to chlorhexidine, which had been used as a disinfectant for handwashing by the medical staff and students of the hospital. 
TABLE 2. Incidence of isolation of strains of serotype 013 and NT from urine samples of patients in each ward

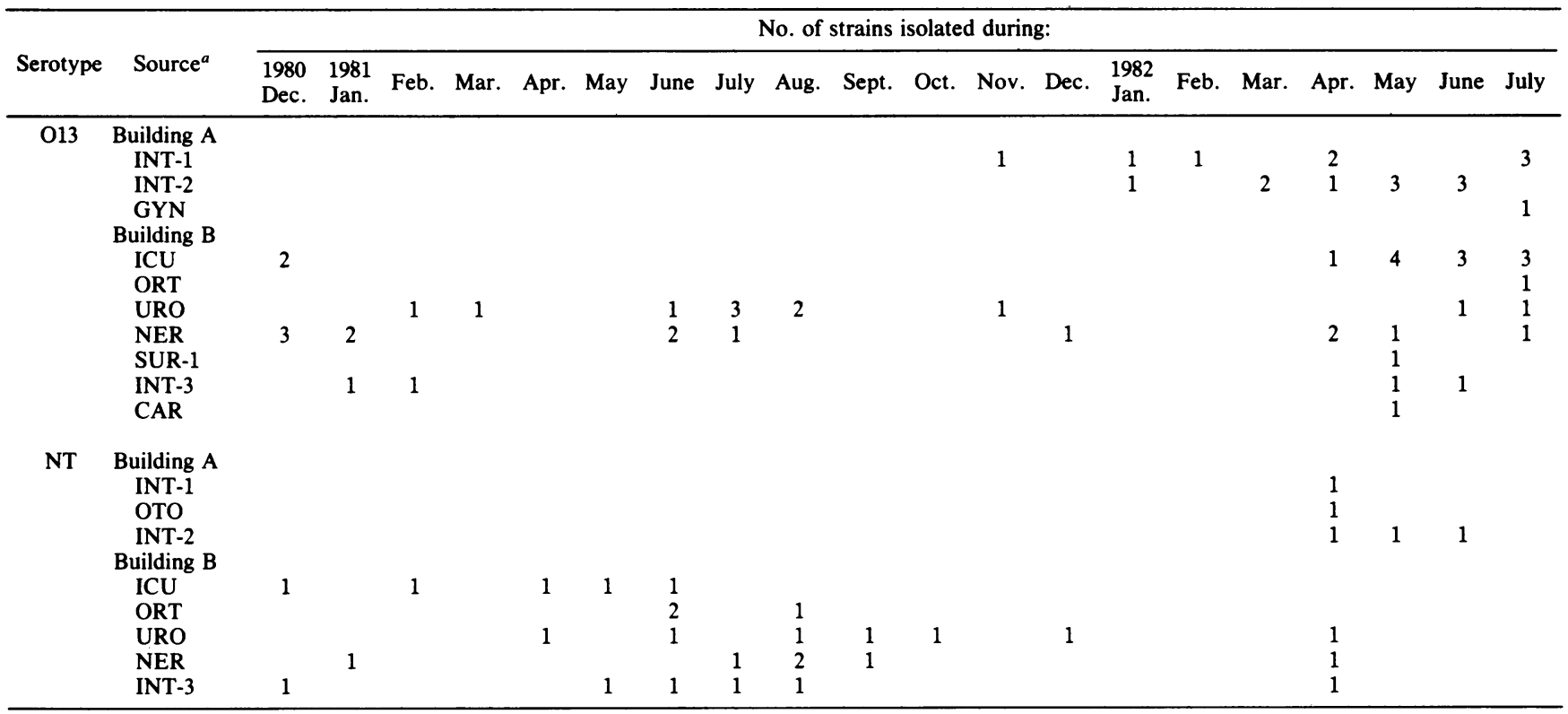

a Abbreviations: First Department of Internal Medicine (INT-1), Second Department of Internal Medicine (INT-2), Third Department of Internal Medicine (INT-3), Gynecology (GYN), Intensive Care Unit (ICU), Orthopedic Surgery (ORT), Urology (URO), Neurosurgery (NER), First Department of Surgery (SUR1), Cardiac and Thoracic Surgery (CAR), and Otorhinolaryngology (OTO).

\section{DISCUSSION}

$S$. marcescens has been established clearly as a cause of serious UTIs in hospitalized patients $(1,4,5,9,11,16,17$, 20-22). The predominant serotypes of clinical isolates varied greatly $(11,16,20)$, except in a few cases in which a single serotype predominated (17). The present prevalence survey revealed an epidemic of four or more serotypes, including a nontypable one, with an interesting possible mode of transmission within a hospital.

It is conceivable that the indigenous Serratia sp. organisms (drug susceptible), living in water or in soil, are brought into a hospital and cause opportunistic infections in high-risk patients, thus defining the serotypes predominating in the hospital (9). Then the organisms in patients acquire resistance to drugs as a result of indiscriminate extensive dosing $(9,16)$. Many strains of clinical isolates of $S$. marcescens are highly resistant to the current antibiotics $(3,5,6,15,17-19$, $22)$, and the drug resistance is known to be transferred to other susceptible bacteria via $R$ plasmids $(4,14,15,18)$, thus introducing a problematic situation in which aminoglycoside antibiotics, including gentamicin and amikacin, which have been employed for the treatment of infections with $S$. marcescens, may no longer be effective. The decrease in the susceptibility of $\mathrm{O} 13$ over time (group A versus group B) to

TABLE 3. Incidence of isolation of strains of serotype $012 / 14$ and $02 / 3$ from urine samples of patients in each ward

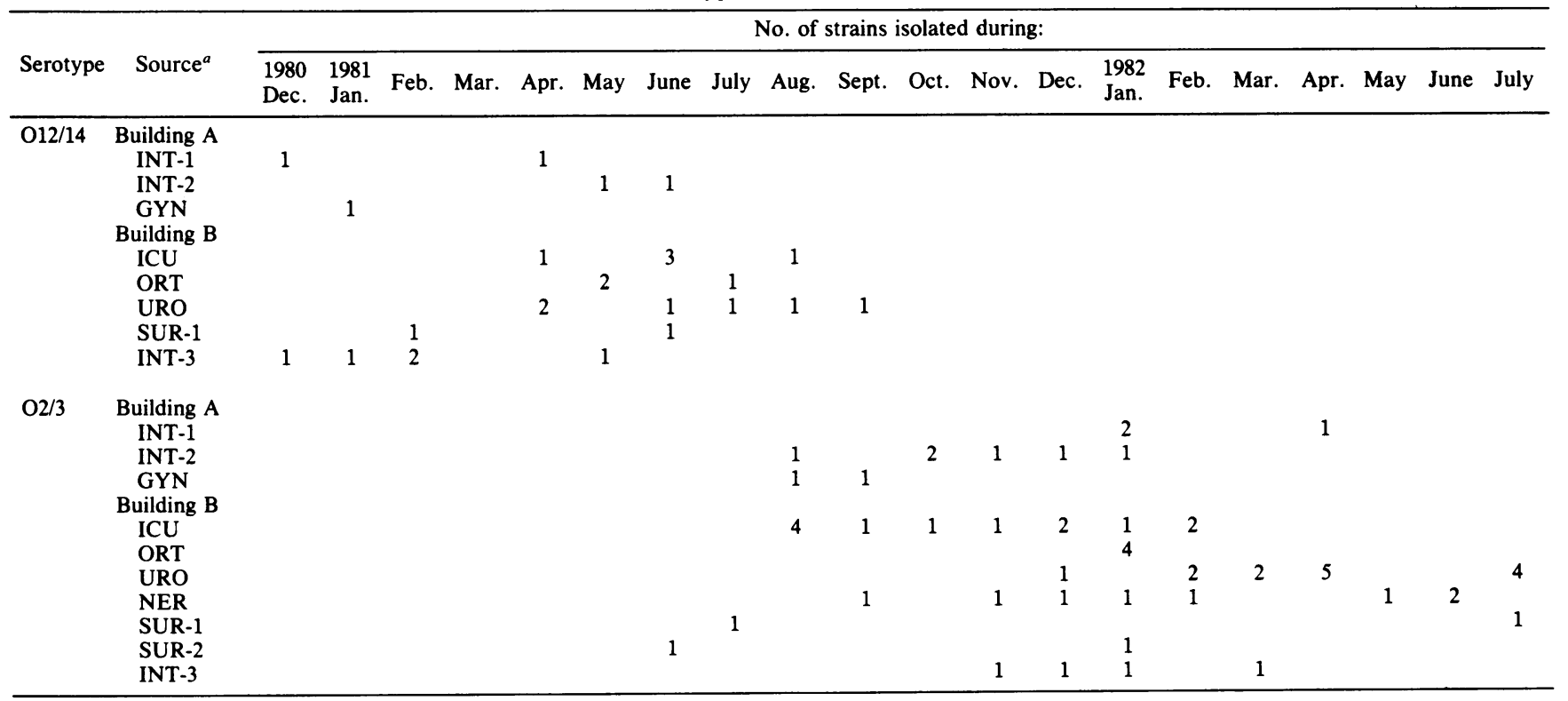

\footnotetext{
${ }^{a}$ Abbreviations are the same as in Table 2.
} 
TABLE 4. Susceptibilities to antibiotics of the major strains of $S$. marcescens isolated from patients in each ward

\begin{tabular}{|c|c|c|c|c|c|}
\hline \multirow{2}{*}{ Drug } & \multirow{2}{*}{ Serotype } & \multirow{2}{*}{$\begin{array}{l}\text { No. of } \\
\text { strains } \\
\text { tested }\end{array}$} & \multicolumn{3}{|c|}{$\operatorname{MIC}(\mu \mathrm{g} / \mathrm{ml})$} \\
\hline & & & Range & $\mathrm{MIC}_{50}$ & $\mathrm{MIC}_{90}$ \\
\hline Sulbenicillin & $\begin{array}{l}\text { O12/14 } \\
\text { O2/3 } \\
\text { O13 } \\
\text { NT }\end{array}$ & $\begin{array}{l}15 \\
52 \\
47 \\
25\end{array}$ & $\begin{array}{r}25->100 \\
12.5->100 \\
25->100 \\
6.25->100\end{array}$ & $\begin{array}{l}>100 \\
>100 \\
>100 \\
>100\end{array}$ & $\begin{array}{l}>100 \\
>100 \\
>100 \\
>100\end{array}$ \\
\hline Cefmetazole & $\begin{array}{l}\text { O12/14 } \\
\text { O2/3 } \\
\text { O13 } \\
\text { NT }\end{array}$ & $\begin{array}{l}15 \\
52 \\
47 \\
25\end{array}$ & $\begin{array}{r}25->100 \\
50->100 \\
12.5->100 \\
1.56->100\end{array}$ & $\begin{array}{r}>100 \\
100 \\
>100 \\
100\end{array}$ & $\begin{array}{l}>100 \\
>100 \\
>100 \\
>100\end{array}$ \\
\hline Gentamicin & $\begin{array}{l}\text { O12/14 } \\
\text { O2/3 } \\
\text { O13 } \\
\text { NT }\end{array}$ & $\begin{array}{l}15 \\
52 \\
47 \\
25\end{array}$ & $\begin{array}{l}1.56-100 \\
3.12->100 \\
1.56->100 \\
1.56->100\end{array}$ & $\begin{array}{c}6.25 \\
50 \\
100 \\
25\end{array}$ & $\begin{array}{r}25 \\
>100 \\
>100 \\
>100\end{array}$ \\
\hline Amikacin & $\begin{array}{l}\text { O12/14 } \\
\text { O2/3 } \\
\text { O13 } \\
\text { NT }\end{array}$ & $\begin{array}{l}15 \\
52 \\
47 \\
25\end{array}$ & $\begin{array}{l}1.56-100 \\
6.25-100 \\
0.78-50 \\
3.12-25\end{array}$ & $\begin{array}{l}25 \\
25 \\
25 \\
25\end{array}$ & $\begin{array}{l}50 \\
50 \\
50 \\
25\end{array}$ \\
\hline Micronomicin & $\begin{array}{l}\text { O12/14 } \\
\text { O2/3 } \\
\text { O13 } \\
\text { NT }\end{array}$ & $\begin{array}{l}15 \\
52 \\
47 \\
25\end{array}$ & $\begin{aligned} & 0.78-12.5 \\
& 1.56-25 \\
& \leq 0.20-50 \\
& \leq 0.20-25\end{aligned}$ & $\begin{array}{l}3.12 \\
6.25 \\
6.25 \\
1.56\end{array}$ & $\begin{array}{l}6.25 \\
25 \\
25 \\
12.5\end{array}$ \\
\hline Ofloxacin & $\begin{array}{l}\text { O12/14 } \\
\text { O2/3 } \\
\text { O13 } \\
\text { NT }\end{array}$ & $\begin{array}{l}15 \\
52 \\
47 \\
25\end{array}$ & $\begin{aligned} & 1.56-12.5 \\
\leq & 0.20-25 \\
\leq & 0.20-25 \\
\leq & 0.20-12.5\end{aligned}$ & $\begin{array}{l}3.12 \\
0.78 \\
6.25 \\
1.56\end{array}$ & $\begin{array}{l}3.12 \\
3.12 \\
12.5 \\
12.5\end{array}$ \\
\hline
\end{tabular}

gentamicin and amikacin may be due in part to the conjugational transfer of the resistance. Gentamicin was active against most of the strains of $012 / 14$ and 013 isolated by September 1981 (group A), and thus the strains of the former serotype may have been eradicated by application of the antibiotic in each ward of the hospital. Furthermore, the strains of $\mathrm{O} 2 / 3$ resistant to gentamicin began to be isolated from patients in June 1981, and they spread rapidly throughout the hospital, appearing to replace the strains of $012 / 14$. However, most strains of the isolates were susceptible to micronomicin and ofloxacin, and so these two antibiotics are expected to take the place of aminoglycoside antibiotics for the treatment of $S$. marcescens infections.

Futhermore, it has been known that outbreaks of nosocomial infections with the organisms are also caused by incorrect use of disinfectants $(7,17)$. Marrie and Costerton (13) described an outbreak of nosocomial infection due to contamination of disinfectant hand soap with $S$. marcescens resistant to $2 \%$ chlorhexidine. This may be the same strain as that observed in this study; most of the isolates, except for those of $012 / 14$, were highly resistant to chlorhexidine.

In a hospital affiliated with a university, it is a major problem that, in addition to the bacterial contamination of medical instruments, the careless movement of medical students or undergraduate nurses from ward to ward for medical or educational purposes can facilitate the transmission of drug-resistant mutants of causative organisms $(8,11$, $16,17)$. In addition, the bed density of a ward has been correlated with the occurrence of nosocomial infections (1). To control nosocomial infections, more careful epidemiological surveys should be required in addition to correct drug selections for patients.

TABLE 5. Changes in MICs of drugs for clinical isolates of $S$. marcescens isolated at different times ${ }^{a}$

\begin{tabular}{|c|c|c|c|c|c|c|}
\hline \multirow{2}{*}{ Drug } & \multirow{2}{*}{ Serotype } & \multirow{2}{*}{ Group } & \multirow{2}{*}{$\begin{array}{l}\text { No. of } \\
\text { strains } \\
\text { tested }\end{array}$} & \multicolumn{3}{|c|}{ MIC $(\mu \mathrm{g} / \mathrm{ml})$} \\
\hline & & & & Range & $\mathrm{MIC}_{50}$ & $\mathrm{MIC}_{90}$ \\
\hline Sulbenicillin & $\begin{array}{l}\text { O12/14 } \\
\text { O2/3 } \\
\text { O13 } \\
\text { NT }\end{array}$ & $\begin{array}{l}\text { A } \\
\text { A } \\
\text { B } \\
\text { A } \\
\text { B } \\
\text { A } \\
\text { B }\end{array}$ & $\begin{array}{r}15 \\
11 \\
41 \\
12 \\
35 \\
17 \\
8\end{array}$ & $\begin{array}{r}25->100 \\
50->100 \\
12.5->100 \\
50->100 \\
25->100 \\
6.25->100 \\
50->100\end{array}$ & $\begin{array}{r}>100 \\
>100 \\
>100 \\
50 \\
>100 \\
>100 \\
>100\end{array}$ & $\begin{array}{l}>100 \\
>100 \\
>100 \\
>100 \\
>100 \\
>100 \\
>100\end{array}$ \\
\hline Cefmetazole & $\begin{array}{l}\text { O12/14 } \\
\text { O2/3 } \\
\text { O13 } \\
\text { NT }\end{array}$ & $\begin{array}{l}\text { A } \\
\text { A } \\
\text { B } \\
\text { A } \\
\text { B } \\
\text { A } \\
\text { B }\end{array}$ & $\begin{array}{r}15 \\
11 \\
41 \\
12 \\
35 \\
17 \\
8\end{array}$ & $\begin{array}{r}25->100 \\
50->100 \\
50->100 \\
100->100 \\
12.5->100 \\
1.56->100 \\
12.5->100\end{array}$ & $\begin{array}{r}>100 \\
100 \\
100 \\
>100 \\
>100 \\
100 \\
100\end{array}$ & $\begin{array}{l}>100 \\
>100 \\
>100 \\
>100 \\
>100 \\
>100 \\
>100\end{array}$ \\
\hline Gentamicin & $\begin{array}{l}\text { O12/14 } \\
\text { O2/3 } \\
\text { O13 } \\
\text { NT }\end{array}$ & $\begin{array}{l}\text { A } \\
\text { A } \\
\text { B } \\
\text { A } \\
\text { B } \\
\text { A } \\
\text { B }\end{array}$ & $\begin{array}{r}15 \\
11 \\
41 \\
12 \\
35 \\
17 \\
8\end{array}$ & $\begin{array}{l}1.56-100 \\
12.5->100 \\
3.12->100 \\
1.56->100 \\
3.12->100 \\
1.56-100 \\
6.25->100\end{array}$ & $\begin{array}{c}6.25 \\
100 \\
25 \\
1.56 \\
100 \\
12.5 \\
25\end{array}$ & $\begin{aligned} & 12.5 \\
&> 100 \\
&> 100 \\
& 100 \\
&> 100 \\
& 100 \\
&>100\end{aligned}$ \\
\hline Amikacin & $\begin{array}{l}\mathrm{O} 12 / 14 \\
\mathrm{O} 2 / 3 \\
\mathrm{O} 13\end{array}$ & $\begin{array}{l}\text { A } \\
\text { A } \\
\text { B } \\
\text { A } \\
\text { B } \\
\text { A } \\
\text { B }\end{array}$ & $\begin{array}{r}15 \\
11 \\
41 \\
12 \\
35 \\
17 \\
8\end{array}$ & $\begin{array}{l}1.56-100 \\
12.5-50 \\
6.25-100 \\
0.78-50 \\
3.12-50 \\
3.12-25 \\
6.25-25\end{array}$ & $\begin{array}{l}25 \\
25 \\
25 \\
3.12 \\
25 \\
25 \\
25\end{array}$ & $\begin{array}{l}50 \\
50 \\
50 \\
6.25 \\
50 \\
25 \\
25\end{array}$ \\
\hline
\end{tabular}


TABLE 5-Continued

\begin{tabular}{|c|c|c|c|c|c|c|}
\hline \multirow{2}{*}{ Drug } & \multirow{2}{*}{ Serotype } & \multirow{2}{*}{ Group } & \multirow{2}{*}{$\begin{array}{l}\text { No. of } \\
\text { strains } \\
\text { tested }\end{array}$} & \multicolumn{3}{|c|}{$\operatorname{MIC}(\mu \mathrm{g} / \mathrm{ml})$} \\
\hline & & & & Range & $\mathrm{MIC}_{50}$ & $\mathrm{MIC}_{90}$ \\
\hline \multirow[t]{7}{*}{ Micronomicin } & O12/14 & A & 15 & $0.78-12.5$ & 3.12 & 6.25 \\
\hline & $\mathrm{O} 2 / 3$ & A & 11 & $3.12-25$ & 25 & 25 \\
\hline & & B & 41 & $1.56-25$ & 6.25 & 12.5 \\
\hline & $\mathrm{O} 13$ & A & 12 & $\leq 0.20-50$ & 0.78 & 12.5 \\
\hline & & B & 35 & $0.39-25$ & 12.5 & 25 \\
\hline & NT & A & 17 & $0.39-12.5$ & 1.56 & 12.5 \\
\hline & & B & 8 & $\leq 0.20-25$ & 6.25 & 25 \\
\hline \multirow[t]{7}{*}{ Ofloxacin } & $012 / 14$ & A & 15 & $1.56-12.5$ & 3.12 & 6.25 \\
\hline & $\mathrm{O} 2 / 3$ & A & 11 & $0.39-12.5$ & 0.78 & 0.78 \\
\hline & & B & 41 & $\leq 0.20-25$ & 0.78 & 3.12 \\
\hline & 013 & A & 12 & $1.56-25$ & 3.12 & 12.5 \\
\hline & & B & 35 & $\leq 0.20-12.5$ & 6.25 & 12.5 \\
\hline & NT & A & 17 & $\leq 0.20-6.25$ & 1.56 & 6.25 \\
\hline & & B & 8 & $\leq 0.20-12.5$ & 0.39 & 12.5 \\
\hline \multirow[t]{7}{*}{ Chlorhexidine } & $\mathrm{O} 12 / 14$ & A & 13 & $\leq 3.12-12.5$ & 3.12 & 12.5 \\
\hline & $\mathrm{O} 2 / 3$ & A & 9 & $\leq 3.12-200$ & 100 & 200 \\
\hline & & B & 40 & $12.5-200$ & 100 & 200 \\
\hline & $\mathrm{O} 13$ & A & 12 & $\leq 3.12-100$ & 6.25 & 100 \\
\hline & & B & 34 & $\leq 3.12-400$ & 12.5 & 200 \\
\hline & NT & $\mathrm{A}$ & 15 & $\leq 3.12-200$ & 6.25 & 200 \\
\hline & & B & 8 & $\leq 3.12-400$ & 6.25 & 400 \\
\hline
\end{tabular}

${ }^{a}$ The strains of each serotype were divided into two groups; group A consisted of strains isolated by September 1981 , when the bacterial substitution of O2/3 for 012/14 was observed, and group B consisted of those isolated subsequently, from October 1981 to July 1982.

\section{LITERATURE CITED}

1. Allen, S. D., and K. B. Conger. 1969. Serratia marcescens infection of the urinary tract: a nosocomial infection. J. Urol. 101:621-623.

2. Altemeier, W. A., W. R. Culbertson, W. D. Fullen, and J. J. McDonough. 1969. Serratia marcescens septicemia: a new threat surgery. Arch. Surg. 99:232-238.

3. Alvarez, J. S., B. Regueiro, and M. J. Garrido. 1979. Antimicrobial susceptibility of clinical isolates of Serratia marcescens. Antimicrob. Agents Chemother. 16:523-524.

4. Ambrosio, R. E., A. J. Van Wyk, and H. C. De Klerk. 1979. Antibiotic-resistant Serratia marcescens infection in a hospital. S. Afr. Med. J. 55:584-587.

5. Arroyo, J. C., W. L. Milligan, B. Postic, J. Northey, E. Parker, and C. S. Bryan. 1981. Clinical, epidemiologic and microbiologic features of a persistent outbreak of amikacin-resistant Serratia marcescens. Infect. Control (Thorofare) 2:367-372.

6. Cooksey, R. C., E. R. Bannister, and W. E. Farrar, Jr. 1975. Antibiotic resistance patterns of clinical isolates of Serratia marcescens. Antimicrob. Agents Chemother. 7:396-399.

7. Dineen, P. 1967. The exchange of skin bacteria between patients and hospital personnel. Surg. Gynecol. Obstet. 125:979-982.

8. Dodson, W. H. 1968. Serratia marcescens septicemia. Arch. Intern. Med. 121:145-150.

9. Farmer, J. J., III, B. R. Davis, and F. W. Hickman. 1976. Detection of Serratia outbreaks in hospital. Lancet ii:455-459.

10. Magnuson, C. W., and H. R. Elston. 1966. Infections caused by nonpigmented Serratia: report of seven cases. Ann. Intern. Med. 65:409-418.

11. Maki, D. G., C. G. Hennekens, C. W. Phillips, W. V. Shaw, and J. V. Bennett. 1973. Nosocomial urinary tract infection with Serratia marcescens: an epidemiologic study. J. Infect. Dis. 128:579-587.

12. Markowitz, S. M., and D. J. Sibilla. 1980. Comparative susceptibilities of clinical isolates of Serratia marcescens to newer cephalosporins, alone and in combination with various amino- glycosides. Antimicrob. Agents Chemother. 18:651-655.

13. Marrie, T. J., and J. W. Costerton. 1981. Prolonged survival of Serratia marcescens in chlorhexidine. Appl. Environ. Microbiol. 42:1093-1102.

14. Medeiros, A. A., and T. F. O'Brien. 1969. Contribution of R factors to the antibiotic resistance of hospital isolates of Serratia, p. 30-35. Antimicrob. Agents Chemother. 1968.

15. Olexy, V. M., T. J. Bird, H. G. Grieble, and S. K. Farrand. 1979. Hospital isolates of Serratia marcescens transferring ampicillin. carbenicillin, and gentamicin resistance to other gram-negative bacteria including Pseudomonas aeruginosa. Antimicrob. Agents Chemother. 15:93-100.

16. Rutala, W. A., V. A. Kennedy, H. B. Loflin, and F. A. Sarubbi, Jr. 1981. Serratia marcescens nosocomial infections of the urinary tract associated with urine measuring containers and urinometers. Am. J. Med. 70:659-663.

17. Schaberg, D. R., R. H. Alford, R. Anderson, J. J. Farmer III, M. A. Melly, and W. Schaffner. 1976. An outbreak of nosocomial infection due to multiply resistant Serratia marcescens: evidence of interhospital spread. J. Infect. Dis. 134:181-188.

18. Traub, W. H., I. Kleber, A. Puhler, and H. Burkhardt. 1976. Characterization of a nosocomially significant, multiple drugresistant strain of Serratia marcescens. Chemotherapy 22:297312.

19. Verbist, L., J. Spaepen, and J. Vandepitte. 1976. In vitro sensitivity of hospital strains of Serratia marcescens to chemotherapeutic agents. Chemotherapy 22:43-54.

20. Wilfert, J. N., F. F. Barrett, W. H. Ewing, M. Finland, and E. H. Kass. 1970. Serratia marcescens: biochemical, serological, and epidemiological characteristics and antibiotic susceptibility of strains isolated at Boston City Hospital. Appl. Microbiol. 19:345-352.

21. Yu, V. L. 1979. Serratia marcescens: historical perspective and clinical review. N. Engl. J. Med. 300:887-893.

22. Yu, V. L., C. A. Oakes, K. J. Axnick, and T. C. Merrigan. 1979. Patient factors contributing to the emergence of gentamicinresistant Serratia marcescens. Am. J. Med. 66:468-472. 